\title{
Hidrocarbonetos policíclicos aromáticos (HPAs) em grãos de milho submetidos à secagem com queimador de cavaco
}

\author{
Polycyclic aromatic hydrocarbons (PHAs) in maize grains subjected to drying with a cavaco burner \\ Hidrocarburos policíclicos aromáticos (HPAs) en granos de maíz sometidos al secado con
} quemador de cavaco

Telvi Marcelo Branco

ORCID: https://orcid.org/0000-0002-2544-0294 Universidade Estadual do Oeste do Paraná, Brasil E-mail: brancomarcelo@gmail.com

Samuel Nelson Melegari de Souza ORCID: https://orcid.org/0000-0002-3581-902X Universidade Estadual do Oeste do Paraná, Brasil E-mail: samuel.souza@unioeste.br

Evandro Marcos Kolling

ORCID: https://orcid.org/0000-0002-9452-6374 Universidade Tecnológica Federal do Paraná, Brasil E-mail: kolling@utfpr.edu.br

Jair Antonio Cruz Siqueira ORCID: https://orcid.org/0000-0002-8140-444X Universidade Estadual do Oeste do Paraná, Brasil E-mail: jair.siqueira@unioeste.br

Luciene Kazue Tokura

ORCID: https://orcid.org/0000-0001-9758-0141 Universidade Estadual do Oeste do Paraná, Brasil E-mail: lucienetokura@gmail.com

\begin{abstract}
Resumo
A queima de qualquer material orgânico pode gerar compostos químicos denominados HPA's, que tem potencial carcinogênico e mutagênico. Esse fato é especialmente importante nos processos de secagem de produtos agrícolas que são empregados direta ou indiretamente na alimentação humana ou animal. Com objetivo de verificar o potencial risco de contaminação por HPA's, e de novos equipamentos vinculados a operação de secagem de produtos agrícolas, o estudo avaliou um sistema moderno de queima de lenha de eucalipto, na forma de cavacos, na secagem artificial de grãos de milho. Para o desenvolvimento do trabalho foram coletas amostras de milho em diferentes dias e umidade de colheita, assim como dados operacionais de secagem, como temperatura, umidade relativa e consumo energético. Com os dados operacionais de secagem, o sistema foi avaliado tecnicamente. Amostras do produto, antes e pós secagem, foram encaminhadas para um laboratório especializado para verificar a presença ou ausência de HPA's. Após as análises verificou-se que tanto a umidade do ar quanto a umidade dos grãos não interferiram na produção de hidrocarbonetos. Entretanto, encontrou-se contaminantes em grãos vindos da lavoura, mas, que não foram potencializados pelo processo de secagem, ficando seus índices abaixo dos limites preconizados internacionalmente. As vantagens quanto ao processo de secagem em cavacos são, automação e consequente diminuição de mão de obra, estabilidade e controle de temperatura, modulação da vazão de ar, economia de combustível e eliminação dos riscos de incêndio. As desvantagens estão no alto custo inicial do sistema, controle dimensional e necessidade de armazenamento coberto dos cavacos.
\end{abstract}

Palavras-chave: Secador de coluna; Queimadores de fogo direto; Umidade.

\begin{abstract}
Burning any organic material can generate chemical compounds called PHA's, which has carcinogenic and mutagenic potential. This fact is especially important in the drying processes of agricultural products that are directly or indirectly used in food or feed. In order to verify the potential risk of contamination by PHA's, and of new equipment linked to the operation of drying agricultural products, the study evaluated a modern system of burning eucalyptus wood, in the form of chips, in the artificial drying of corn grains. For the development of the work, corn samples were collected in different days and harvest humidity, as well as operational drying data, such as temperature, relative humidity, and energy consumption. With the operational drying data, the system was technically evaluated. Samples of the product, before and after drying, were sent to a specialized laboratory to verify the presence or absence of PHA's. After the analysis, it was verified that both the humidity of the air and the moisture of the grains did not interfere in the production
\end{abstract}


of hydrocarbons. However, contaminants were found in grains coming from the crop, but they were not potentialized by the drying process, keeping their indices below internationally recommended limits. The advantages regarding the chip drying process are automation and consequent decrease of labor, stability and temperature control, modulation of air flow, fuel economy and elimination of fire risks. The drawbacks are the high initial cost of the system, dimensional control, and the need for chip-covered storage.

Keywords: Column dryer; Direct fire burners; Humidity.

\section{Resumen}

La quema de cualquier material orgánico puede generar compuestos químicos llamados HPA's, que tienen potencial carcinogénico y mutagénico. Este hecho es especialmente importante en los procesos de secado de productos agrícolas se utilizan directa o indirectamente en la alimentación humana o animal. Con el objetivo de verificar el risco potencial de contaminación por HPA's, y de nuevos equipos vinculados a la operación de secado de productos agrícolas, el estudio evaluó un moderno sistema de quema de madera de eucalipto, en forma de astillas, en el secado artificial de granos de maíz. Para el desarrollo del trabajo se recolectaron muestras de maíz en diferentes días y humedad de cosecha, así como datos operativos de secado, como temperatura, humedad relativa y consumo energético. Con los datos operativos de secado, se evaluó tecnicamente el sistema. Las muestras del producto, antes y después del secado, se enviaron a un laboratorio especializado para verificar la presencia o ausencia de HPA's. Luego del análisis se verificó que tanto la humedad del aire como la humedad del grano no interfirieron en la producción de hidrocarburos. Sin embargo, se encontraron contaminantes en granos provenientes del cultivo, pero que no fueron potencializados por el proceso de secado, con índices por debajo de los límites recomendados internacionalmente. Las ventajas en cuanto al proceso de secado en astillas son, automatización y consecuente recucción de mano de obra, control de la estabilidad y temperatura, modulación del flujo de aire, ahorro de combustible y eliminación de riesgos de incendio. Las desventajas son el alto costo inicial del sistema, el control dimensional y la necesidad de almacenamiento de chips cubierto.

Palabras clave: Secador de columna; Quemadores de fuego directo; Humedad.

\section{Introdução}

O Brasil é o terceiro maior produtor mundial de milho (Zea mays L.), superado apenas pelos Estados Unidos e pela China, com uma produção de 96 milhões de toneladas na safra 2018/2019 e chegando a 103 milhões de toneladas na safra 2019/2020 (CONAB, 2020) e a destinação principal são as indústrias de rações para animais com em torno de 50\% da produção (Abimilho, 2021).

Após a colheita e a secagem devem ser armazenados em lugares apropriados como silos e ou armazéns (Coradi, Lacerda, Chaves \& Melo, 2015) que operam com diversos processos que vão desde a retirada de impurezas, a redução da umidade para conservar o produto e a facilidade no modelo de transporte (Ferrari, 2006), tudo isto para não ocorra alterações na sua qualidade nem perdas, que podem chegar a 7,1\% como no ano de 2016 segundo a Organização das Nações Unidas para a Alimentação e a Agricultura FAO (2020) devido à falta de técnicas, instalações de armazenamento inadequadas, danos causados por insetos, roedores e outras pragas, problemas relacionados à comercialização, logística e transporte (Rosegrant, Magalhaes, ValmonteSantos \& D’Croz, 2015).

Rosegrant et al. (2015) cita ainda que a capacidade estática de armazenagem de um país deve ser igual ou superior a 1,2 vezes a sua produção agrícola anual. No Brasil, a capacidade estática de armazenagem de grãos é de aproximadamente 162 milhões de toneladas, sendo que a produção de grãos é de aproximadamente 226 milhões de toneladas (CONAB, 2018), o que implica em perdas qualitativas e quantitativas do produto final até a distribuição aos consumidores (Coradi et al., 2015).

A secagem de grãos é um processo simultâneo de transferência de calor e massa entre o produto e o ar de secagem. A remoção do teor de água deve ser feita a nível tal que os grãos permaneçam em equilíbrio com ar do ambiente onde serão armazenados (Silva, Afonso \& Donzelles, 2000). Ainda segundo os mesmos autores, este processo deve ocorrer de maneira a preservar a aparência e a qualidade nutritiva dos grãos como alimento e sua viabilidade como semente. Oliveira Filho (1986) cita que na secagem de grãos, o método mais utilizado é a secagem artificial em altas médias e ou baixas temperaturas, e que o consumo de energia neste método de secagem pode chegar a $60 \%$ ou mais do total de energia consumido na produção e processamento do produto. 
O processo de secagem depende dos secadores e de sua operação. Estes são equipamentos térmico/mecânicos e dentro de um conjunto. Para obter um bom rendimento de secagem são necessários uma boa e dimensionada fornalha, o ciclone de captação bem regulado, e um exaustor que produza um volume de ar suficiente, pois o ar é um dos itens principais na secagem (Puzzi, 1986).

Os secadores apresentam diferentes modelos, variando em função do combustível utilizado para aquecimento do ar, diferente movimentação do ar e dos grãos. Quanto ao sistema de secagem artificial, podem ser contínuos ou intermitentes (Weber, 2005).

Um secador é formado por um funil de carga que é por onde o grão a ser seco é recebido e distribuído uniformemente na câmara de secagem; uma torre de secagem, formada por painéis e dutos abertos ou fechados intercalados. O secador pode ser de cavaletes (mais antigos) ou em colunas, por onde passa a massa de grãos verticalmente e recebendo o fluxo de ar quente aquecido na fornalha e insuflado no secador, que proporcionará a secagem destes grãos. Apresentam sensores para monitoramento das temperaturas internas e do ar de secagem (Silva, 2004). Um dos requisitos de maior importância no projeto de fornalhas é o volume da câmara de combustão, pois toda a energia proveniente da combustão deve ser incorporada aos gases num volume suficiente para que se desenvolva a chama e se complete a combustão, antes que os gases quentes possam se exaurir (Serfaty, 2007).

Conforme Silva et al. (2000) Fatores como a umidade relativa e temperatura do ar ambiente, a temperatura e o fluxo do ar de secagem, a umidade inicial e final do grão, o fluxo do produto no secador, estão relacionados com a velocidade de secagem e com a qualidade final dos grãos secos. Os autores esclarecem que os principais fatores que interferem no desempenho e rendimento dos secadores são o teor de umidade inicial e final do produto a ser seco, a temperatura do ar de secagem, a resistência oferecida ao fluxo de ar (vazão), a temperatura e umidade relativas do ambiente, a natureza da fonte de energia da fornalha, o sistema de carga do secador e as características dos ventiladores do secador.

A combustão completa é o processo que leva as substâncias combustíveis à sua forma mais oxidada e, a incompleta é o processo no qual os produtos de combustão são constituídos, em partes, por formas que representam oxidação parcial dessas substâncias (Serfaty, 2007).

Vlassov (2001) afirma que para uma melhor queima de combustíveis sólidos finos, o melhor processo é a queima em suspensão. Esta queima deve ocorrer tomando o cuidado para que as partículas mais finas de combustível e os gases não sejam arrastados pelo ar puxado para dentro do sistema (Vlassov, 2001). Todo o processo de queima acontece na câmara de combustão em um tempo muito curto, isto faz com que o tempo de permanência do combustível na câmara de combustão seja muito pequeno. Como os combustíveis sólidos se queimam a partir da superfície, deve-se aumentar a área de superfície do combustível em contato com o ar para se elevar a potência de uma fornalha (Melo, 2010). Cada combustível possui propriedades térmicas diferentes, portanto o tamanho e a forma de uma fornalha dependem da quantidade de calor desejada em um intervalo de tempo, além do combustível a ser utilizado.

Segundo Nascimento (2007) com a utilização do cavaco é possível reduzir o custo da energia térmica em comparação com o uso da lenha, pois o cavaco permite maior automação do processo gerando diminuição na mão de obra, e melhor uniformidade de queima, o que impacta diretamente no custo final da secagem de grãos.

A granulometria ideal é definida em função das necessidades energéticas do sistema e das características do queimador, levando em consideração a velocidade ideal da reação de queima (Ceragioli, 2013). Pereira (2000) cita que quanto menor o tamanho de uma partícula, maior é a superfície de contato da mesma e maior é a velocidade da queima e sua reação de combustão.

Quanto à contaminação, a Organização das Nações Unidas para Agricultura e Alimentação (FAO) estima que 25 \% dos grãos no mundo estejam contaminados (FAO, 2006). O que pode acontecer de diversas formas, como sementes contaminadas 
por fungos, através do solo, através de resíduos de herbicidas, ou ainda no fator pós-colheita, na secagem ou no armazenamento (Brooker, Bakker-Arkema \& Hall, 1992).

A contaminação de alimentos por substâncias tóxicas tem sido pesquisada nos últimos anos, e diversas classes de compostos químicos de diferentes origens vêm sendo encontradas em alimentos e bebidas, dentre elas os Hidrocarbonetos Policíclicos Aromáticos (HPAs) (Camargo \& Toledo, 2002).

Estes, são oriundos da queima de combustíveis fósseis e madeira e também durante os processos que utilizam derivados de petróleo (Ravindra, Sokhi \& Van Grieken, 2008). Para a formação destes compostos depende alguns fatores como tipo da biomassa ou combustível utilizado, quantidade e qualidade de Oxigênio disponível, pressão e, principalmente, do calor, pois a concentração de HPAs aumenta linearmente na faixa de temperatura de $400{ }^{\circ} \mathrm{C}$ a $1000{ }^{\circ} \mathrm{C}$ (Conde, Ayala, Afonso \& Gonzalez, 2004).

Os HPAs são formados a partir de compostos como os carboidratos, os peptídeos e o gás metano; além destes, também compostos insaturados e estruturas cíclicas podem colaborar para a sua formação (Evangelista, 2001).

São dezesseis Hidrocarbonetos os principais de acordo com a União Européia (UE) e pela United States Environmental Protection Agency (USEPA) como poluentes prioritários de acordo com a toxicidade e a frequência de exposição em seres humanos (Debastani \& Iavanovi, 1999). Destes, sete são identificados pela International Agency for Research on Cancer - IARC como cancerígenos para animais e pela USEPA como potencialmente cancerígenos para seres humanos, sendo eles: pireno, benzo(a)antraceno, benzo(a)pireno, dibenzo(a,h)antraceno, indeno(1, 2, 3-cd)pireno, benzo(b)fluoranteno e benzo(k)fluoranteno (USEPA, 1998).

No Brasil, o que existe são algumas Portarias e Resoluções Normativas da ANVISA que determinam limite de B(a)P (benzo(a)antraceno) somente para alimentos que passaram por processo de defumação. A Resolução RDC n²/2007 estabeleceu limite de 0,03 $\mu \mathrm{g} / \mathrm{kg}$ para B(a)P (benzo(a)antraceno) em alimentos adicionados de aroma de fumaça, e a Portaria n⿳518/2004, juntamente com a Resolução RDC n²74/2005, estabeleceram limite de 0,7 $\mu \mathrm{g} / \mathrm{L}$ para água envasada e gelo (ANVISA, 2007), para grãos ainda não há legislação específica.

A escolha pelos grãos de milho se deu pela importância comercial do produto na alimentação humana, assim como a preocupação em evidenciar poluentes que podem ocasionar problemas de saúde como moléculas cancerosas através de Hidrocarbonetos Policíclicos que podem ser produzidos através do processo de secagem ineficiente ou de outras fontes anteriores a secagem, assim, como testar se a queima a cavaco de lenha poderia aumentar estes índices.

\section{Metodologia}

A metodologia foi organizada em etapas, sendo a coleta dos grãos de milho, o processo de secagem com queimador a cavaco, análise dos grãos de milho em laboratório especializado, Campinas, Estado de São Paulo, e análise quali-quantitativas dos dados.

Os grãos de milho da segunda safra 2020 foram recebidos na Cooperativa Consolata - Copacol. A Cooperativa possui uma de suas filiais, a de Melissa, localizada na região sul, no Município de Cascavel, Oeste do Paraná. A estrutura contempla um conjunto de três silos metálicos com capacidade de armazenagem de $3.000 \mathrm{t}$ cada um, possui também um conjunto de dois secadores de grãos com capacidade de secagem nominal de $150 \mathrm{t} \mathrm{h}^{-1}$, e um fluxo de recepção de $240 \mathrm{th}^{-1}$, através de máquinas de limpeza, transportadores horizontais (redlers), transportadores verticais (Elevadores de grãos) além de duas moegas de $90 \mathrm{t}$ cada uma (Copacol, 2021).

De maneira geral utilizou-se para a produção deste processo balança comercial, homogeneizador, medidor marca Dickey John, modelo GAC-2100, secador de grãos e queimador para cavaco. 
Os grãos foram colhidos com colhedora automatizada, nas datas intercaladas de 08, 11, 12, 27 e 28 de agosto de 2020.Tendo início a partir das 09 h30 horas da manhã até às $19 \mathrm{~h} 00$. As datas de coleta destas amostras de grãos se deram em virtude das condições climáticas, com clima chuvoso na região escolhida, não permitindo que a colheita se desse em dias sequenciais e sim em dias alternados. Estes grãos foram previamente limpos em máquina de pré-limpeza, rotativa, marca Comil, com capacidade de $240 \mathrm{t} \mathrm{h}^{-1}$, equipada com sistema de peneiras e ar até atingirem $1 \%$ de impurezas e ou materiais estranhos.

Os grãos chegaram úmidos, e para a determinação do grau de umidade das amostras antes da secagem foram retiradas em um único ponto na saída do silo Pulmão, em porções de $1 \mathrm{~kg}$ de grãos em sacos plásticos, com intervalos de 1 hora entre elas, durante $8 \mathrm{~h} /$ dia e por 5 dias alternados, estas serviram de parâmetro de comparação com as amostras retiradas posterior a secagem.

Foram organizadas um total de 39 amostras de $1 \mathrm{~kg}$, distribuídos de acordo com as coletas que foram 8 amostras no primeiro dia, 8 amostras no segundo dia, 7 amostras no terceiro dia, 8 amostras no quarto dia e 8 amostras no quinto dia. Ao final de cada dia, as amostras retiradas durante o dia, foram homogeneizadas em um homogeneizador de amostras, modelo quarteador, marca Meditec, configurando uma única amostra para o dia de $4 \mathrm{~kg}$ de peso, antes da secagem e outra de $4 \mathrm{~kg}$ da coleta após a secagem que foram identificados e armazenados sob refrigeração $\left(0^{\circ} \mathrm{C}\right)$. Permaneceram até o final dos cinco dias de coleta, quando foram encaminhados ao laboratório de análises técnicas. As amostras posteriores a secagem foram retiradas em um único ponto na saída do secador e seguindo a mesma metodologia de antes da secagem.

Para a retirada da umidade utilizou-se secador de grãos modelo Kepler Weber ADS 150, ano 2018, de colunas, com capacidade nominal de $150 \mathrm{t} \mathrm{h}^{-1}$, as secagens foram de forma contínua, automática, com recirculação do ar de resfriamento, com descarga mecânica por bandejas basculantes, ventiladores na posição superior. A Temperatura do ar de secagem foi monitorada por três termômetros Termopar tipo K, instalados dentro do secador, marca e modelo NBRtec, dispostos na entrada do ar de secagem, outro no interior da massa de grãos e o terceiro na exaustão do secador, ou seja, na saída do ar de secagem.

O processo de secagem de grãos é simples, porém exige qualidade, acompanhamento e resultados eficientes para que os grãos mantenham sua integridade nutritiva e o mínimo de alterações e ou contaminantes e poluentes.

Os grãos de milho após serem descarregados na moega, são transportados por elevadores de grãos até um equipamento que faz a pré-limpeza dos grãos através de peneiras. Após a pré-limpeza, os grãos são acondicionados em um silo pulmão, onde aguardam a secagem e ocorre um equilíbrio da umidade contida nos grãos, o que melhora o desempenho e a regulagem do secador de grãos. Após cheio, o sistema de calor é ligado. Ventiladores instalados na parte superior do secador "puxam" o ar do queimador, provocando uma pressão negativa no interior do secador, o ar ambiente passa pelo queimador de cavacos e é aquecido a uma temperatura que pode chegar a $450{ }^{\circ} \mathrm{C}$, o ar superaquecido segue para um sistema onde se mistura ao ar ambiente, abaixando a temperatura do ar que normalmente retorna e passa a ser menos de $100^{\circ} \mathrm{C}$ para não ocasionar danos aos grãos.

Dados referentes à temperatura do ar de entrada, temperatura da massa de grãos, temperatura de saída do ar, umidade relativa do ambiente e temperatura do ambiente foram coletadas a cada 1 hora.

$O$ processo de secagem se deu de forma direta, quando o ar de secagem entra em contato direto com as fuligens da queima, e pode contaminar o produto seco com Hidrocarbonetos Policíclicos Aromáticos.

O combustível utilizado foi o cavaco de lenha de eucalipto (Eucalyptus sp.) com pedaços de em torno de 5,0 cm, medidos com trena métrica no início e no final do dia para saber o montante gasto.

O queimador marca Imtab de fogo direto (8,6 Gcal) Modelo Hércules FIP 80, ano 2019, com capacidade de produção de $8.600 .000 \mathrm{kcal} \mathrm{h}^{-1}$. Termostato controla a alimentação da fornalha mantendo uma média de $90{ }^{\circ} \mathrm{C}$ no ar de secagem.

O laboratório buscou analisar a presença e ou ausência de Hidrocarbonetos nos grãos de milho, coletados antes e depois do processo de secagem das amostras, objetivo principal deste trabalho. O laboratório considerou os seguintes limites na amostra: não aplicável; **<LD: Menor que o Limite de Deteç̧̃a de $0,6 \mu \mathrm{g} \mathrm{kg}^{-1} \mathrm{e}^{* * *}<\mathrm{LQ}$ : Menor que o Limite de Quantificação $1,0 \mu \mathrm{g}$ $\mathrm{kg}^{-1}$. Os resultados foram enviados através de laudo de Ensaios Laboratoriais. Os principais Hidrocarbonetos citados pela USEPA 
e avaliados nas amostras foram: Acenafteno, Acenaftileno, Antraceno, Benzo(a)antraceno, Benzo(a)pireno, Benzo(b)fluoranteno, Benzo(g,h,i), Benzo(k)fluoranteno, Criseno, Dibenzo(a,h)antraceno, Fenantreno, Fluoranteno, Indeno (1,2,3-c,d) pireno, Naftaleno, PAH's Totais e Pireno.

Buscou-se verificar se a queima com cavaco de lenha que alimenta a fornalha, em condições controladas de temperatura, umidade e pressão produz ou não Hidrocarbonetos que são carcinogênicos à saúde.

A análise estatística dos dados foi realizada pelo programa estatístico Sisvar (Ferreira, 2011). A comparação das médias das variáveis foi comparada pelo teste de Tukey a 5\% de significância.

\section{Resultados e Discussão}

Os resultados se referem aos dados que envolvem os grãos de milho, ao processo de secagem com combustível de cavaco de lenha de eucalipto (Eucalyptus sp.) e a eficiência do processo de secagem em relação a queima eficiente e com consequência a não produção de Hidrocarbonetos.

Durante o período de retirada de amostras, que se deu em agosto de 2020, as temperaturas não foram fatores determinantes, pois em apenas um dia teve-se temperaturas mais baixas. Em anos mais frios os grãos chegam com umidades mais elevadas para secagem o que poderia restringir o processo de secagem, alguns dias chuvosos, por vezes atrasaram ou adiaram a colheita, não permitindo que se fizessem as coletas de amostras em dias subsequentes e nos mesmos horários.

De posse dos dados de temperatura do ar ambiente, umidade do ar ambiente, vazão do ar ambiente, vazão do ar de secagem, temperatura do ar de secagem do secador e umidade dos grãos de acordo com os dias de coleta, obteve-se os resultados obtidos nas Tabelas 1, 2, 3, 4, 5 e 6 .

Com base na Tabela 1, é possível verifica que as temperaturas variaram entre a menor de $14,7{ }^{\circ} \mathrm{C}$ no horário de $16 \mathrm{~h} 30$ no terceiro dia de coleta e a maior correspondente a $29,8^{\circ} \mathrm{C}$ no penúltimo dia às $15 \mathrm{~h} 30$, um clima um pouco atípico para a região. Em alguns horários não houve recebimento de grãos portanto não houve medição. A média das temperaturas sem manteve em $14,26^{\circ} \mathrm{C}$ durante os cinco dias de análise.

Após a apresentação dos dados de coleta considerou-se que os grãos de milho passaram por uma amplitude térmica e climática variada, visto que a estação do inverno é geralmente seca e fria, ainda assim houve dias com umidades relativas bastante altas e variações. Após análise, aplicou-se a Anova nos dados com o intuito de verificar se houve ou não variações dentro das médias encontradas (Tabela 2).

Em relação a temperatura do ar ambiente observou-se que o valor do dia 12 de agosto de $15,1{ }^{\circ} \mathrm{C}$ foi o menor dentre as médias (seguidas pelas mesmas letras minúsculas na coluna) que ficaram em $23,77^{\circ} \mathrm{C}$ e não diferiram entre si quando a análise se deu por horário e pelo Teste de Tukey a 5\% de significância.

Já para a análise da umidade do ar ambiente verificou-se que ficou em torno de 43,34\% em média e também quando analisada nos horários de coleta, e a umidade do dia 12 de agosto diferiu mais que o dobro das demais estando em 95,44\% quando analisadas pelo Teste Tukey a 5\% de significância. 
Tabela 1. Temperatura do ar ambiente nos dias de coleta $\left({ }^{\circ} \mathrm{C}\right)$.

\begin{tabular}{cccccc}
\hline & \multicolumn{5}{c}{ Data de coleta } \\
\cline { 2 - 6 } Horário & $08 / 08$ & $11 / 08$ & $12 / 08$ & $27 / 08$ & $28 / 08$ \\
\hline $09: 30$ & - & - & - & 22 & - \\
$10: 30$ & 18,4 & - & 15,6 & 23 & - \\
$11: 30$ & 23,2 & 25,7 & 15,4 & 24,8 & - \\
$12: 30$ & 24,3 & 26,4 & 15,9 & 27,4 & - \\
$13: 30$ & 24,7 & 27,5 & 14,6 & 28 & 27 \\
$14: 30$ & 25,2 & 28,3 & 14,8 & 29,6 & 28,7 \\
$15: 30$ & 25,4 & 27,8 & 14,8 & 29,8 & 0 \\
$16: 30$ & 25,4 & 27,3 & 14,7 & 27,6 & 29,2 \\
$17: 30$ & 25,4 & 24,8 & - & - & 27,8 \\
$18: 30$ & - & 23 & - & - & 24,4 \\
$19: 30$ & - & - & - & - & 23,8 \\
$20: 30$ & - & - & - & - & 21 \\
$21: 30$ & - & - & - & 24,4 \\
\hline
\end{tabular}

Fonte: Autores.

Tabela 2. Temperatura e umidade do ar ambiente nos dias de coleta.

\begin{tabular}{ccc}
\hline Data de coleta & Temperatura $\left({ }^{\circ} \mathrm{C}\right)$ & Umidade $(\%)$ \\
\hline $08 / 08$ & $24,00 \mathrm{a}$ & $32,41 \mathrm{~b}$ \\
$11 / 08$ & $26,35 \mathrm{a}$ & $31,49 \mathrm{~b}$ \\
$12 / 08$ & $15,11 \mathrm{~b}$ & $95,44 \mathrm{a}$ \\
$27 / 08$ & $26,52 \mathrm{a}$ & $29,12 \mathrm{~b}$ \\
$28 / 08$ & $25,79 \mathrm{a}$ & $34,76 \mathrm{~b}$ \\
\hline Média & 23,77 & 43,34 \\
CV $(\%)$ & 9,68 & 16,71 \\
DMS & 3,36 & 10,58 \\
\hline
\end{tabular}

Fonte: Autores.

Os percentuais de umidade relativa do ar tiveram boas variações, indo de $100 \%$ às $15 \mathrm{~h} 30$ no dia 12 de agosto, terceiro dia de coleta à $23 \%$ às $15 \mathrm{~h} 30$ do dia 27 de agosto, clima seco, favorável a secagem dos grãos (Tabela 3).

O processo de secagem de grãos é aplicado para reduzir o teor de umidade em base úmida dos produtos agrícolas, então, fatores climáticos como temperatura ambiente e umidade relativa do ar tem influência direta no rendimento da secagem (Dias, 2015). Para Silva (2004) e Dias (2015) grãos e sementes são produtos higroscópicos, e como tais, recebem ou enviam vapor de água do ar que os cerca.

Em relação às temperaturas foram avaliadas em três pontos específicos, denominados $\mathrm{P} 1, \mathrm{P} 2 \mathrm{e}$ P3, dentro do secador de grãos. Na Tabela 4 pode ser observado o equilíbrio nos dados. 
Tabela 3. Umidade do ar ambiente nos dias de coleta.

\begin{tabular}{cccccc}
\hline & \multicolumn{5}{c}{ Umidade relativa do ar ambiente $(\%)$} \\
\hline Horário & $08 / 08$ & $11 / 08$ & $12 / 08$ & $27 / 08$ & $28 / 08$ \\
\hline \cline { 2 - 6 } $09: 30$ & 56,1 & - & - & 36 & - \\
$10: 30$ & 38,8 & - & 90,7 & 34,6 & - \\
$11: 30$ & 33,7 & 34 & 89 & 32 & - \\
$12: 30$ & 27,9 & 31,4 & 94 & 27,2 & - \\
$13: 30$ & 28,8 & 28,1 & 97,3 & 26,6 & 30,8 \\
$14: 30$ & 24 & 24,5 & 98,4 & 26,2 & 30,7 \\
$15: 30$ & 25 & 26,4 & 100 & 23 & \\
$16: 30$ & 25 & 30,5 & 98,7 & 27,4 & 28,8 \\
$17: 30$ & - & 37,8 & - & - & 30,6 \\
$18: 30$ & - & 39,2 & - & - & 24,3 \\
$19: 30$ & - & - & - & - & 38,4 \\
$20: 30$ & - & - & - & - & 47 \\
$21: 30$ & - & - & - & 47,5 \\
\hline
\end{tabular}

Fonte: Autores.

Tabela 4. Temperatura nos três pontos dentro do secador de acordo com os dias de coleta.

\begin{tabular}{|c|c|c|c|c|c|c|c|c|c|c|c|c|c|c|c|}
\hline \multicolumn{16}{|c|}{ Temperatura $\left({ }^{\circ} \mathrm{C}\right)$} \\
\hline \multirow[b]{3}{*}{ Horário } & \multicolumn{15}{|c|}{ Dias de coleta } \\
\hline & \multicolumn{3}{|c|}{ Dia 01} & \multicolumn{3}{|c|}{ Dia 02} & \multicolumn{3}{|c|}{ Dia 03} & \multicolumn{3}{|c|}{ Dia 04} & \multicolumn{3}{|c|}{ Dia 05} \\
\hline & $\mathrm{P} 1$ & $\mathrm{P} 2$ & P3 & $\mathrm{P} 1$ & $\mathrm{P} 2$ & P3 & $\mathrm{P} 1$ & $\mathrm{P} 2$ & P3 & $\mathrm{P} 1$ & $\mathrm{P} 2$ & P3 & $\mathrm{P} 1$ & $\mathrm{P} 2$ & P3 \\
\hline 09:30 & - & - & - & - & - & - & - & - & - & 63 & 84 & 37 & - & - & - \\
\hline $10: 30$ & 60 & 74 & 28 & - & - & - & 86 & 96 & 35 & 79 & 96 & 36 & - & - & - \\
\hline $11: 30$ & 80 & 97 & 33 & 69 & 89 & 34 & 86 & 96 & 32 & 81 & 96 & 34 & - & - & - \\
\hline $12: 30$ & 83 & 97 & 34 & 97 & 83 & 33 & 86 & 97 & 34 & 81 & 95 & 33 & - & - & - \\
\hline $13: 30$ & 92 & 92 & 33 & 65 & 77 & 30 & 87 & 95 & 33 & 82 & 96 & 34 & 74 & 93 & 36 \\
\hline $14: 30$ & 82 & 91 & 32 & 77 & 93 & 33 & 87 & 96 & 35 & 83 & 97 & 34 & 74 & 95 & 34 \\
\hline $15: 30$ & 85 & 97 & 34 & 85 & 99 & 38 & 88 & 97 & 37 & 86 & 98 & 35 & - & - & - \\
\hline $16: 30$ & 86 & 97 & 34 & 82 & 87 & 35 & 56 & 82 & 28 & 85 & 97 & 35 & 74 & 94 & 34 \\
\hline $17: 30$ & - & - & - & 79 & 87 & 34 & - & - & - & 79 & 87 & 34 & 77 & 78 & 33 \\
\hline $18: 30$ & - & - & - & 81 & 92 & 34 & - & - & - & - & - & - & 71 & 69 & 34 \\
\hline $19: 30$ & - & - & - & - & - & - & - & - & - & - & - & - & 64 & 72 & 34 \\
\hline $20: 30$ & - & - & - & - & - & - & - & - & - & - & - & - & 80 & 94 & 35 \\
\hline $21: 30$ & - & - & - & - & - & - & - & - & - & - & - & - & 78 & 95 & 34 \\
\hline
\end{tabular}

Fonte: Autores.

Quanto às temperaturas dentro do secador foram avaliadas em três pontos diferentes, três medidores, e se apresentaram como no ponto 1 localizado no interior da massa de grãos, a menor temperatura de $56{ }^{\circ} \mathrm{C}$ no horário de $16 \mathrm{~h} 30$; no terceiro dia de 
análise, logo que se iniciou a secagem e a maior de $92{ }^{\circ} \mathrm{C}$ no horário de $13 \mathrm{~h} 30$, e a maior foi de $97{ }^{\circ} \mathrm{C}$ no horário de $12 \mathrm{~h} 30$ no segundo dia de coleta. No ponto 2 , localizado na entrada do ar de secagem, a menor foi de $72{ }^{\circ} \mathrm{C}$, no último dia da secagem às $19 \mathrm{~h} 30$, e a maior temperatura de $99^{\circ} \mathrm{C}$ atingida às $15 \mathrm{~h} 30$ do segundo dia de análise. No ponto 3 , localizado no ar de exaustão do secador, a menor foi de $28^{\circ} \mathrm{C}$, no início da secagem às $10 \mathrm{~h} 30$, também no terceiro dia as $16 \mathrm{~h} 30$, e a maior de $38^{\circ} \mathrm{C}$, alcançada no segundo dia às $15 \mathrm{~h} 30$.

No ponto1 a média das temperaturas se manteve em $79,23{ }^{\circ} \mathrm{C}$, no ponto 2 ficou em $90,94{ }^{\circ} \mathrm{C}$ e no terceiro ponto ficou em $33,82^{\circ} \mathrm{C}$. A secagem ocorreu com uma temperatura ambiente menor no início e aumentando gradativamente até atingir suas máximas no ponto2, ou seja, na massa de grão, sendo bastante reduzida ao final do processo. $\mathrm{O}$ equipamento apresentou bom rendimento de secagem, sem interrupções devido a falhas mecânicas. Toledo e Marcos-Filho (1977) afirma que no processo de secagem é preciso considerar a temperatura do ar, ainda mais se tratando de sementes, pois temperaturas altas podem reduzir a germinação e o vigor das sementes. Para Botelho et al. (2018) o clima é determinante na quantidade de material a ser seco. Chuvas no pré-colheita causam atrasos na colheita e dificultam a perda natural de umidade dos grãos, ainda segundo os autores, a secagem de milho $2^{\mathrm{a}}$ safra depende de características climáticas na região, período de semeadura da cultura e clima. Elias (2002) afirma que se deve controlar a temperatura do ar de secagem, dentro de limites de $80^{\circ} \mathrm{C}$ e $100{ }^{\circ} \mathrm{C}$, para evitar danos aos grãos como a super secagem (Silva et al., 2000; Kepler Weber, 2010; Dias, 2015).

A secagem é a etapa de maior gasto energético no beneficiamento, seja pelo gasto com energia elétrica seja pela queima do combustível, logo sob o ponto de vista financeiro é o maior custo dentro da unidade. Para Lima (2014) o custo com combustíveis (lenha + eletricidade), na etapa de secagem de grãos de milho, pode representar até 10,35\% do valor de venda do produto beneficiado. $\mathrm{O}$ mesmo autor afirma ainda que grãos de milho secados com temperatura do ar de $80{ }^{\circ} \mathrm{C}$ apresentaram menor custo energético.

Brooker et al. (1992) afirma que quanto maior for à temperatura ambiente e maior a vazão de ar do secador, e menor for a umidade relativa do ar de secagem, menor será o tempo necessário para secagem do produto, e para cada tipo de cereal, o tempo de secagem será maior quanto mais alta for a umidade inicial e mais baixa for a umidade final do produto desejada. De Grandi (1999) chegou à mesma conclusão quando testou um secador vertical de camada fixa com diferentes intervalos. Nem sempre as condições climáticas são favoráveis e os grãos também não são colhidos em condições ideais, fatores que influenciam diretamente no rendimento dos secadores (Dias, 2015).

Os teores de umidade de entrada dos grãos podem ser observados na Tabela 5.

Para as umidades de entrada dos grãos a menor umidade foi no segundo dia, às $14 \mathrm{~h} 30$ de $19,5 \%$ e a maior foi de 29,8\% no quarto dia de secagem às $15 \mathrm{~h} 30$. A média ficou em 22,41\% para os grãos. Segundo Silva (2004) a umidade em base úmida, ou teor de água, é a relação percentual entre a quantidade de água presente no produto e a quantidade de produto.

Para as umidades de saída dos grãos os resultados podem ser observados na Tabela 6.

Para as umidades de saída dos grãos a menor foi no quarto dia, às $12 \mathrm{~h} 30$ de 15,6\% e a maior foi de 19,3\% no quarto dia de secagem às 15 h30. A média ficou em 17,26\% para os grãos. Segundo o manual do Secador da Kepler Weber (2010) traz como ideal de colheita para os percentuais de umidade parâmetros entre $18 \%$ e $20 \%$ de umidade, e seja seco até chegar a $14 \%$, entretanto há diversos fatores como clima, colheita, maquinários, equipamentos, região que promovem muitas variações destes percentuais. 
Research, Society and Development, v. 10, n. 13, e465101321564, 2021

(CC BY 4.0) | ISSN 2525-3409 | DOI: http://dx.doi.org/10.33448/rsd-v10i13.21564

Tabela 5. Umidade de entrada dos grãos de acordo com os dias de coleta.

\begin{tabular}{cccccc}
\hline \multicolumn{5}{c}{ Umidades de entrada dos grãos (\%) } \\
\hline Horário & Primeiro & Segundo & Terceiro & Quarto & Quinto \\
\cline { 2 - 6 } 09:30 & - & - & - & 23,7 & - \\
$10: 30$ & 24,2 & - & 22,5 & 24,5 & - \\
$11: 30$ & 25,2 & 24 & 21,8 & 25,8 & - \\
$12: 30$ & 20 & 23,3 & 23,7 & 20,1 & - \\
$13: 30$ & 20,3 & 20,4 & 22 & 20,5 & 25 \\
$14: 30$ & 22,4 & 19,5 & 24,1 & 25 & 23,1 \\
$15: 30$ & 25,2 & 22,4 & 22,7 & 29,8 & 0 \\
$16: 30$ & 23,7 & 22,1 & 20,3 & 26,2 & 22,5 \\
$17: 30$ & - & 24,2 & - & - & 22,4 \\
$18: 30$ & - & 21,5 & - & - & 20,4 \\
$19: 30$ & - & - & - & - & 22,5 \\
$20: 30$ & - & - & - & - & 24 \\
$21: 30$ & - & - & & - & 23,1 \\
\hline
\end{tabular}

Fonte: Autores.

Tabela 6. Umidade de saída dos grãos de acordo com os dias de coleta.

\begin{tabular}{|c|c|c|c|c|c|}
\hline \multicolumn{6}{|c|}{ Umidades de saída dos grãos (\%) } \\
\hline \multirow[b]{2}{*}{ Horário } & \multicolumn{5}{|c|}{ Dias de coleta } \\
\hline & Primeiro & Segundo & Terceiro & Quarto & Quinto \\
\hline 09:30 & - & - & - & 16,2 & - \\
\hline $10: 30$ & 18,6 & - & 16,8 & 16,6 & - \\
\hline $11: 30$ & 15,8 & 18,3 & 16,2 & 17,4 & - \\
\hline $12: 30$ & 17,2 & 18,2 & 17,5 & 15,6 & - \\
\hline $13: 30$ & 17,5 & 17,2 & 16,6 & 15,8 & 18,5 \\
\hline $14: 30$ & 18,4 & 16,8 & 17,8 & 17,3 & 17,5 \\
\hline $15: 30$ & 17,3 & 17,7 & 16,6 & 19,3 & 17,3 \\
\hline $16: 30$ & 17,6 & 17,4 & 16,1 & 17,8 & 17,1 \\
\hline $17: 30$ & - & 18,6 & - & - & 16,9 \\
\hline $18: 30$ & - & 17,4 & - & - & 16,6 \\
\hline $19: 30$ & - & - & - & - & 17,1 \\
\hline $20: 30$ & - & - & - & - & 17,2 \\
\hline $21: 30$ & - & & - & - & 17,5 \\
\hline
\end{tabular}

Fonte: Autores.

O combustível utilizado neste queimador é o cavaco de lenha em torno de $5 \mathrm{~cm}$, encontrava-se em boas condições físicas, com poucas impurezas e com pedaços uniformes. Nogueira et al. (2000) cita que a maior reatividade da madeira em cavacos, se comparada à madeira em toras, aumenta a eficiência em fornalhas ou queimadores para geração de energia térmica, 
tornando-se mais eficientes, se trabalhados com granulometrias variando entre 5, 0 a 10,0 cm. Diniz (2014) afirma que quanto menores forem as dimensões dos cavacos, maior será a superfície da madeira exposta, o que favorece o sistema e também contribui com o menor desperdício de galhos finos e ponteiras (Grunkaut, 2012).

Verificou-se que as partículas menores entram em combustão mais rapidamente, diminuindo o tempo de queima. Quanto à umidade do cavaco neste processo se manteve em uma média de $40 \%$. Cabe citar que o tempo de armazenamento deste material é recente na unidade. O cavaco proveniente de tora apresenta umidade alta quando recém-picado. A umidade pode variar de $29,5 \%$ a $67,3 \%$ da base verde ao pátio. No decorrer de 30 dias a umidade pode decrescer para $25,5 \%$ a $62,1 \%$ e ao longo de 120 dias de $9,5 \%$ a 47,6\% de teor de umidade base úmida (Brand et al., 2004).

Realizando a análise de gastos do cavaco, verificou-se que para uma necessidade de $8.600 .000 \mathrm{kcal}$, chegou-se a um gasto de $56,50 \mathrm{~kg} \mathrm{~h}^{-1}$ de cavaco. Se considerados os valores comerciais praticados na região, tem-se $\mathrm{R} \$ 150,00 \mathrm{ton}^{-1}$ de cavaco e $\mathrm{R} \$ 120,00$ ton $^{-1}$ de lenha, então tem-se um valor de $\mathrm{R} \$ 8,50 \mathrm{~h}^{-1}$ para o cavaco e $\mathrm{R} \$ 3,10 \mathrm{~h}^{-1}$ para lenha. Radin e Maia (2015) analisando os custos de cavaco de lenha concluiu que um secador $\mathrm{kW} 100$ com necessidade de $7.240 .000 \mathrm{kcal} \mathrm{h}^{-1} \mathrm{gastou}_{56,92}$ $\mathrm{kg} \mathrm{h}^{-1}$ de cavaco. Para a quantificação do cavaco utilizado durante o processo de secagem, foi inicialmente medido o volume, e ao final de cada dia de secagem a sobra foi novamente medida, por diferença obteve-se a quantidade de cavaco $\left(\mathrm{m}^{3}\right)$ consumida na operação de secagem, em média foi de $11,30 \mathrm{~m}^{3}$ de cavaco para secagem de 1.000 sacas de milho.

Apesar do valor do cavaco ser superior, tem-se que considerar outros fatores como qualidade de secagem, automação do sistema e diminuição do passivo de funcionários, e consequentemente menor risco de acidentes de trabalho. Considerando outra unidade da cooperativa com o mesmo maquinário, porém com fornalha a lenha utiliza seis funcionários por turno a mais que o sistema a cavaco.

Quanto ao rendimento da secagem, o queimador com a temperatura de $90{ }^{\circ} \mathrm{C}$ foi considerada a ideal. Uma vez que a umidade de saída dos grãos de milho ficou entre 16,8 e 17,7\%, considerando que os grãos passaram apenas uma vez pelo secador e necessitando um complemento de secagem para armazenagem segura, como a seca-aeração no silo.

Para Radin e Maia (2015) em seu estudo sobre o Poder Calorífico Inferior (PCI) da Lenha de eucalipto e do cavaco da lenha do eucalipto, chegou aos números de $3.200 \mathrm{kcal} \mathrm{kg}^{-1}$ para a lenha e $4.100 \mathrm{kcal} \mathrm{kg}^{-1}$ para o cavaco, isto ainda segundo ele se deve a maior área específica do cavaco, o que facilitaria a queima do mesmo.

Em relação aos Hidrocarbonetos, os dados encontrados foram enviados pelo laboratório em forma de laudos técnicos de resultados das análises diárias de entradas e saídas de amostras dos grãos, contendo as informações sobre a presença e ou ausência de Hidrocarbonetos. Neste estudo comprovou-se a presença de Hidrocarbonetos em todas as amostras testadas.

No total, o laboratório realizou 180 ensaios laboratoriais, 90 (noventa) anteriores à secagem e outros 90 (noventa) posteriores à secagem. Todas as amostras apresentaram microgramas de Hidrocarbonetos, porém em 93,7\% estes valores abaixo do Limite de Detecção (LD) é de 0,6 $\mu \mathrm{g} \mathrm{kg}^{-1}$ e outros 6,3\% se mantiveram dentro do Limite de Quantificação (LQ) que é de $1,0 \mu \mathrm{kg}^{-1}$, os encontrados foram: Benzo(g,h,i)perileno, Indeno(1,2,3-c,d)pireno e de PAH's Totais nos grãos de entrada e Benzo(a)fluoranteno, Benzo(a)pireno e PAH's Totais nos grãos após a secagem artificial.

Ambos os limites não foram ultrapassados nos quatro primeiros dias nas amostras de entrada para nenhum dos 16 HPAs prioritários de acordo com a United States Environmental Protection Agency (USEPA, 1998). No quinto e último dia, verificouse na amostra antes da secagem o aparecimento de Benzo(g,h,i)perileno, Indeno(1,2,3-c,d)pireno e PAH's Totais que é a soma de todos os principais HPAs. Na data de 28 de agosto, último dia de coleta verificou-se a presença de Benzo(g,h,i)perileno, de Indeno(1,2,3-c,d)pireno e de PAH's Totais. Estes são considerados carcinogênicos de acordo com a USEPA, PHA'S são os mais comuns, e sugere a nomenclatura de totais. Nesta pesquisa comprovou-se a presença e ou ausência, e não foram mensuradas as quantidades dentro destes parâmetros comparativos, o que sugere uma posterior pesquisa. 
Esta variação no resultado anterior ao processo de secagem pode ter vindo de vários fatores, como poluição de beira de estrada, queima de vegetação e solos já contaminados (Toledo \& Camargo, 1998), sementes contaminadas por fungos, através de resíduos de herbicidas, ou ainda no fator pós-colheita, na secagem, no armazenamento ou no processo pelo qual passou (Brooker et al., 1992). Na lavoura, durante o cultivo, pode ocorrer à deposição de HPAs, contaminando as frutas, vegetais e cereais ou até mesmo em pastagens, isto ocorre na origem e também podem ocorrer no processamento, seja durante o processamento e limpeza dos produtos, ou no uso de água contaminada (Harvey, 1996).

São lançados para o ambiente por processos de combustão incompleta de matéria orgânica, produtos de petróleo, efluentes Industriais e esgotos sanitários. Harvey (1996) complementa afirmando que a contaminação dos grãos pode ocorrer durante os tratamentos térmicos severos a que estes grãos são submetidos, como a secagem direta com madeira e a desidratação. Neste estudo a secagem foi direta, entretanto com cavaco de lenha e não houve o aumento de Hidrocarbonetos. Cabe ressaltar que a quantificação deste parâmetro de avaliação necessita de um novo estudo e de uma nova avaliação laboratorial para quantificar os dados.

Com relação às amostras coletadas após a secagem houve uma alteração no dia 11 de agosto, segundo dia para benzo(a)fluoranteno e benzo(a)pireno que saíram do Limite de Detecção para o Limite de Quantificação (Figura 1). Já no dia 28 de agosto, quinto e último o Limite de Quantificação que tinha sido atingido para HPAS totais na amostra antes da secagem, assim permaneceu, já os outros dois Hidrocarbonetos são diferentes em sua cadeia carbônica.

Figura 1. Ocorrência de HPAs em amostras de milho antes e após a secagem.

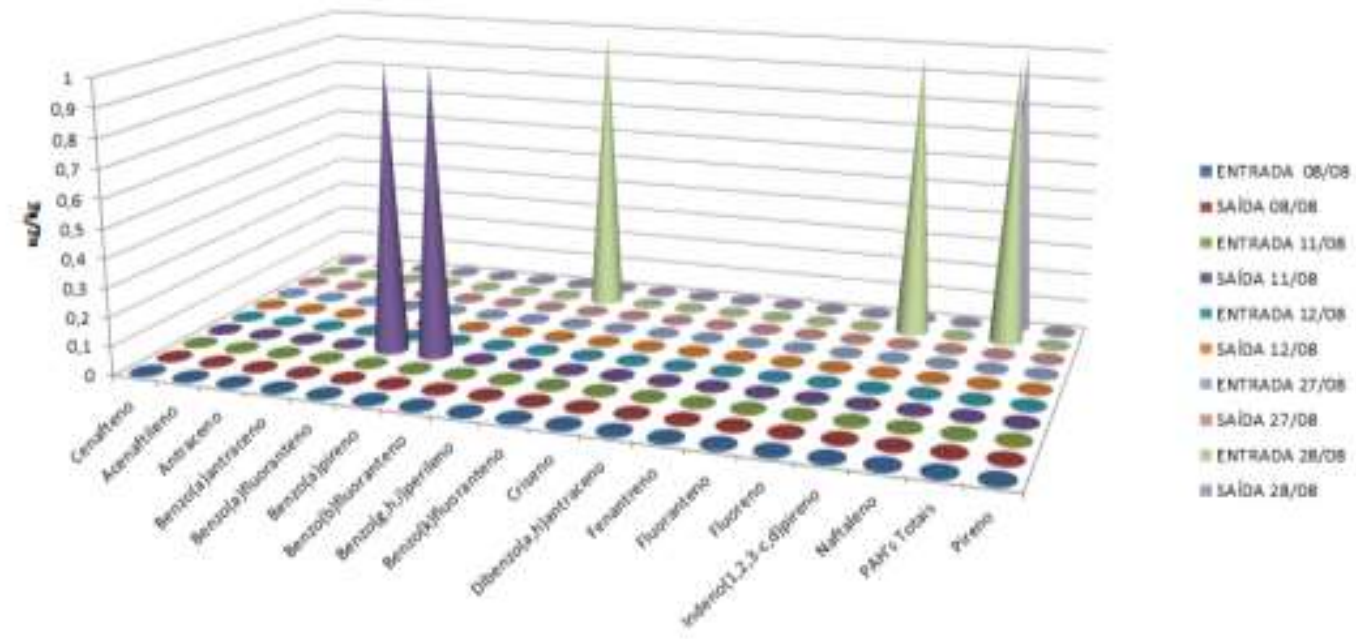

Fonte: Autores.

Entradas e saídas de grãos mostram que foram encontradas variações nos tipos de Hidrocarbonetos e também nos limites. Estas variações se devem a fatores como a contaminação durante o processo de secagem, ao tipo e umidade de combustível, a temperatura, a contaminação dos grãos antes de entrarem na Unidade de beneficiamento.

Resultados ainda bem abaixo dos limites estabelecidos pela União Europeia e muito abaixo de outros trabalhos realizados com a lenha em toras como material combustível. Lima (2014) cita que ao verificar amostras de milho seco em secador com fornalha a lenha com fogo direto, em diferentes temperaturas de secagem, encontrou valores muito superiores aos permitidos em alimentos, cerca de 100 vezes a mais.

A maior média de umidade de entrada no processo de secagem dos grãos se apresentou no quarto dia, o que poderia gerar dentro do processo o aparecimento de Hidrocarbonetos acima do limite, entretanto permaneceram dentro do limite de $0,6 \mu \mathrm{g} \mathrm{kg}^{-1}$. Já na menor média de entrada de umidade de grãos, ou seja, mais secos ocorreu o contrário, detectou-se a mudança 
dos paramentos. Assim, pode-se afirmar também que o clima não foi fator influenciador na produção ou não de HPA, pois no terceiro dia com as menores temperaturas ambientes e maiores umidades relativas do ar, o que exigiu uma carga maior de combustível para manter a temperatura, os resultados apresentaram-se inferiores ao limite de detecção da norma.

De maneira geral pode-se inferir que os grãos podem chegar à unidade de beneficiamento contaminados com diferentes Hidrocarbonetos e diferentes quantidades devido ao ar, ao solo, a água, e devido também ao processo de cultivo e manejo da lavoura desde o plantio até a colheita. Cabe citar que estes itens não foram avaliados neste trabalho, cabe pesquisa posterior.

Garcia (2015) avaliando amostras de soja (Glycine max) vendidas em estabelecimentos comerciais verificou que algumas apresentaram contaminação por HPA's e diferentes concentrações, sendo que grãos cultivados no Estado de São Paulo apresentaram a maior contaminação sendo de 202,46 $\mu \mathrm{g} \mathrm{kg}^{-1}$, no Paraná $38,78 \mu \mathrm{g} \mathrm{kg}^{-1}$, e no Rio Grande do Sul 35,22 $\mu \mathrm{g} \mathrm{kg}^{-1}$. Comparando as regiões avaliadas, observa-se que São Paulo por ser industrializada se apresenta com mais poluentes que possivelmente contenham HPA's contaminando os grãos, já neste estudo onde a região é essencialmente agrícola, encontrou-se valores insignificantes comparativamente.

A temperatura de secagem se manteve constante durante os cinco dias, em torno de $90{ }^{\circ} \mathrm{C}$, o que culminou em não variações e oscilações, este equilíbrio contribuiu para o não aumento de Hidrocarbonetos. Lima (2014) afirma que o maior percentual de Hidrocarbonetos em grãos ocorreu em temperaturas menores que $60{ }^{\circ} \mathrm{C}$, comparando com as temperaturas utilizadas neste processo, consideradas maiores, houve poucos Hidrocarbonetos. $\mathrm{O}$ autor ainda analisou secagem a temperaturas de 40,60 e $80^{\circ} \mathrm{C}$, afirma que grãos de milho submetidos ao processo de secagem em fornalha direta com uso da lenha como combustível são contaminados com HPAs. Já Bertinetti et al. (2018) pesquisando a secagem a lenha em arroz afirmou que a secagem não é fator determinante na produção de HPA's em grãos. Lima (2014) confirma também a não relevância da temperatura no processo, desde que até os limites já testados não está diretamente relacionada à produção de Hidrocarbonetos, e sim, o combustível e a eficiência do processo são mais relevantes.

Bakker-Arkema (1978) constatou que o processo de secagem é não linear e difícil de ser controlado em escala comercial, porém, outros autores como Martinazzo et al. (2007) dizem que para uma secagem econômica, rápida e segura deve-se monitorar e controlar os fenômenos físicos que ocorrem no processo. Estes fatores contribuem para o alcance de uma queima completa dentro do queimador, a qual se buscou comprovar neste estudo. Rodrigues (2010) reafirma que os controles da temperatura, umidade relativa e fluxo do ar de secagem aumenta a eficiência termodinâmica da secagem, ocasionando o menor percentual de danos aos grãos, e também o combustível.

A automação da alimentação de combustível com cavaco e a regulagem das entradas de ar corretas do sistema, propiciam a manutenção da temperatura da queima e este processo em consonância reduz a produção de fumaça, e com consequência menor ou nenhum percentual de produção de Hidrocarbonetos.

Neste caso, a ocorrência no segundo dia da amostra onde apareceram os Hidrocarbonetos Benzo(a)fluoranteno, Benzo(a)pireno pode ser atribuída ao processo de queima incompleta decorrente de uma má regulagem do sistema. Apesar de o sistema ser em grande parte automatizado, outra parte da regulagem exige mão de obra qualificada para que o controle contínuo do sistema seja eficiente, ou seja, para que a máquina seja operada de forma eficiente, ocorrendo a queima completa que não produz hidrocarbonetos. Estas regulagens variam de acordo com as condições climáticas como a qualidade e o tipo do combustível e com a umidade do produto, porém estes fatores nem sempre são considerados relevantes.

Em função do aparecimento de Hidrocarbonetos na entrada e diminuição na saída das amostras, pode ser devido ao fato de que a molécula química de determinados Hidrocarbonetos pode ter reagido no processo e terem sido absorvidos Lopes e Andrade (1996) citam que os HPAs são quimicamente inertes, porém, quando reagem, participam de reações de substituição eletrofílica e de adição. No caso das reações de adição, os compostos formados tendem a sofrer reações de eliminação, o que explica a redução de Hidrocarbonetos vistos nesta análise. 
Quanto aos PHA's totais encontrados no último dia de coleta, na entrada e saída dos grãos atribuiu-se a soma de todos os demais Hidrocarbonetos presentes, que isoladamente não atingiram o Limite de Detecção, porém quando somados se apresentam no Limite de Quantificação das amostras.

Cabe ressaltar também que no Brasil não há legislação sobre o tema, o que também sugere mais pesquisas e avaliações para que sejam estabelecidos parâmetros seguros de comparação em relação aos possíveis malefícios, assim como de conhecimento dos diferentes tipos de Hidrocarbonetos contidos nos grãos que viram alimentos e são consumidos mundialmente.

Segundo Biagi (1998) o comércio internacional de grãos é definido pelas qualidades de grãos como umidade, porcentagem de inteiros, cor, presença de matérias estranhas e imperfeições. Já Sartori (2001) propõe incorporarem-se a estes fatores, outros como os teores de proteína e óleo, dureza, massa específica, histórico do produto e posteriormente análises químicas como HPA.

Neste trabalho verificou-se a condição da queima a cavaco e se esta queima produz ou não Hidrocarbonetos. Todos os demais itens citados merecem estudos futuros, individualizados e aprofundados, devido à relevância da saúde dos humanos e da manutenção do meio ambiente.

\section{Conclusão}

O sistema com queimador a cavaco para secagem de grãos é uma tecnologia relativamente nova, com poucos anos no mercado, entretanto tem se mostrado eficiente na secagem e melhor que a lenha.

No processo de beneficiamento dos grãos, a etapa da secagem com cavaco produziu Hidrocarbonetos, em índices abaixo dos limites utilizados pelas normas internacionais, isto pode ter sido devido a uma queima incompleta, por uma má regulagem no sistema ou excesso de umidade no combustível.

Ao final da secagem a média de umidade dos grãos foi de $17 \%$, o que não é recomendado para armazenagem que é $14 \%$, sugere-se um complemento como seca aeração.

Comprovou-se nesta pesquisa que a secagem com cavacos não aumenta os percentuais de Hidrocarbonetos, mas os grãos podem sair da lavoura e ou chegar na unidade contaminados.

Se faz necessários novos e específicos estudos para contribuir com a apresentação de dados que levam a criação de parâmetros e Legislações sobre o tema e assuntos relacionados.

Comprovou-se nesta pesquisa que não só a secagem incompleta pode produzir hidrocarbonetos, mas os grãos podem sair da lavoura e ou chegar na unidade de recepção já contaminados. Assim, as sugestões para trabalhos futuros é que sejam realizados mais estudos, observações práticas e análises técnicas em todas as etapas da cadeia produtiva do milho para obtenção de dados reais, técnicos e científicos e não somente sobre os hidrocarbonetos, como também de outros poluentes e contaminantes.

\section{Referências}

Abimilho. (2021). Oferta e demanda de milho no Brasil. Abimilho estatísticas. p. 2. http://www.abimilho.com.br/estatisticas/oferta.

ANVISA. (2007). Agência Nacional de Vigilância Sanitária. Resolução da Diretoria Colegiada - RDC nº 2 , de 15 de janeiro de 2007 . Regulamento Técnico sobre Aditivos Aromatizantes. http://portal.anvisa.gov.br/wps/wcm/connect/9a67750047457f218ac0de3fbc4c6735/R DC2_2007.pdf?MOD=AJPERES.

Bakker-Arkema, F. W., Lerwe, L. E., Brook, R. C., \& Brooker, D. B. (1978). Energy and capacity performance evaluation of grain dryers. ASAE, 13p.

Biagi, J. D. (1998). Implicações na Granulometria de Ingredientes na qualidade de peletes e na economia da produção de rações. In: Simpósio sobre granulometria de ingredientes e rações para aves e suínos, 1998, Concórdia, SC.

Bertinetti, I. A., Ferreira, D. C., Monks, J. L. F., Sanches-Filho, P. J., \& Elias, M. C. (2018). Accumulation of polycyclic aromatic hydrocarbons (PAHs) in rice subjected to drying with different fuels plus temperature, industrial processes and cooking. Journal of Food Composition and Analysis, 66, 109-115. 10.1016/j.jfca.2017.12.009

Botelho, F. M., Faria, B. E. M., Botelho, S. C. C., Ruffato, S., \& Nogueira, R. M. (2018). Metodologias para determinação de massa específica de grãos. Revista Agrarian, 11 (41), 251-259. 10.30612/agrarian.v11i41.7922 
Brand, M. A., Klock, U., Muñiz, G. I. B., \& Silva, D. A. (2004). Avaliação do processo produtivo de uma indústria de manufatura de painéis por meio do balanço de material e do rendimento da matéria-prima. Revista Árvore, 28 (4), 553-562. 10.1590/S0100-67622004000400009

Brooker, D. B., Bakker-Arkema, F. W., \& Hall, C. W. (1992). Drying and storage of grains and oilseeds. Van Nostrand Reinhold. 450p.

Camargo, M. C. R., \& Toledo, M. C. F. (2002). Avaliação da contaminação de diferentes grupos de alimentos por hidrocarbonetos policíclicos aromáticos. Brazilian Journal of Food Technology, 5 (76), 19-26.

Ceragioli, N. S. (2013). Qualidade de cavacos produzidos em sistemas florestais de curta rotação de eucalipto para fins energéticos. Dissertação de Mestrado. Universidade Estadual Paulista "Júlio De Mesquita Filho", Botucatu.

CONAB. (2018). Companhia Nacional de Abastecimento. Brasil deverá colher 226 milhões de toneladas de grãos. Conab.

CONAB. (2020). Companhia Nacional de Abastecimento. Perspectivas para a agropecuária. v6. Conab. http://www.conab.gov.br.

Conde, F. J., Ayala, J. H., Afonso, A. M., \& Gonzalez, V. (2004). Optimization of a sampling method to determine polycyclic aromatic hydrocarbons in smoke from incomplete biomass combustion. Analytica Chimica Acta, 524, (1-2), 287-94. 10.1016/j.aca.2004.04.063

Copacol. Descrição da Cooperativa. https://www.copacol.com.br/copacol/historia.

Coradi, P. C., Lacerda Filho, A. F., Chaves, J. B. P., \& Melo, E. C. (2015). Quantification of physical losses products in a plant of feed. Engenharia na Agricultura, 23, 105-118. 10.13083/reveng.v23i2.421

Debastani, R. \& Iavanovi, I. N. (1999). A compilation of physical spectroscopic and photophysical properties of polycyclic aromatic hydrocarbons. Photochemistry and Photobiology, 70 (1), 10-34. 10.1111/j.1751-1097.1999.tb01945.x

De Grandi, A. M. (1999). Avaliação da eficiência de secagem de café (Coffea arabica L.), em secador de camada fixa vertical com revolvimento mecânico. Tese de Doutorado. Engenharia Agrícola, Universidade Federal de Viçosa, Minas Gerais. 61p.

Dias, E. D. (2015). Metodologia de cálculo da capacidade de secagem dos secadores de coluna. Trabalho de conclusão de curso. Departamento de Ciências Exatas e Engenharias, Universidade Regional do Noroeste do Estado do Rio Grande do Sul, Panambi.

Diniz, I. S. (2014). Estudo da Influência da Umidade no consumo específico do Cavaco de Madeira Para Geração de Vapor Saturado em Caldeira de Biomassa. Monografia. Programa de Especialização em Engenharia de Produção da Gerência de Pesquisa e Pós-Graduação, Universidade Tecnológica Federal do Paraná, Ponta Grossa

Elias, M. C. (2002). Fatores que influenciam a aeração e o manejo da conservação de grãos. In: Lorini, I. et al. (Ed). Armazenagem de grãos. Campinas: IBG, p. 311-359.

Evangelista, J. (2001). Tecnologia de alimentos. (2a ed.), Atheneu. 652p.

FAO. (2006). Food and Agriculture Organization of the United Nations Better information sharing could reduce post-harvest food losses. New database launched 2006. Rome: FAO. http://www.fao.org/es.

FAO. (2020). Food and Agriculture Organization. Guidelines on the measurement of harvest and post-harvest losses - Estimation of crop harvest and postharvest losses. In: Malawi Maize. Rice and groundnuts. Field test report. Rome: FAO. p. 37.

Ferrari, R. C. (2006). Utilização de modelo matemático de otimização para identificação de locais para instalação de unidades armazenadoras de soja no estado do Mato Grosso. Dissertação de Mestrado. Escola Superior de Agricultura Luiz de Queiroz, Universidade de São Paulo, Piracicaba.

Ferreira, D. F. (2011.) Sisvar: A computer statistical analysis system. Ciência e Agrotecnologia, 35, 1039-1042. 10.1590/S1413-70542011000600001

Garcia, L. P. (2015). Detecção de fumonisinas e hidrocarbonetos policíclicos aromáticos em grãos de soja (Glycine max L.) e efeito de diferentes temperaturas de secagem. Dissertação de Mestrado. Universidade Federal de Santa Catarina, Florianópolis.

Grunkraut, M. (2012). Cavacos. Coopermiti. http://www.coopermiti.com.br/educacao/cavaco.pdf.

Harvey, G. R. (1996). Mechanisms of carcinogenesis of polycyclic aromatic hydrocarbons. Polycyclic Aromatic Compounds, 9, (1-4), 1-23. $10.1080 / 10406639608031196$

Kepler Weber. (2010). Manual de Operação do Secador KW ADS. Panambi, RS: Elaborado por Daniel Schimidt. 70p.

Lima, R. F. (2014). Qualidade de Grãos de Milho Submetidos a Secagem com Lenha em Diferentes Temperaturas e Períodos de Armazenamento. Dissertação de Mestrado. Universidade Federal do Rio Grande do Sul, Porto Alegre.

Lopes, W. A., \& Andrade, J. B. (1996). Fontes, formação, reatividade e quantificação de hidrocarbonetos policíclicos aromáticos (HPA) na atmosfera. Química Nova, 19 (5), 497-516.

Martinazzo, A. P., Corrêa, P. C., Resende, O., Melo, E. C. (2007). Análise e descrição matemática da cinética de secagem de folhas de capim-limão. Revista Brasileira de Engenharia Agrícola Ambiental, 11 (3), 301-306. https://doi.org/10.1590/S1415-43662007000300009

Melo, F.A.O. (2010). Desenvolvimento e construção de fornalha para biomassa com sistema de aquecimento direto e indireto do ar. Acta Scientiarum. Technology, 32 (2), 129-136. 10.4025/actascitechnol.v32i2.1575.

Nascimento, M. D. (2007). Otimização do uso de lenha e cavaco de madeira para produção de energia em agroindústria Seropédica. Dissertação de Mestrado. Universidade Estadual Paulista, Botucatu. 
Research, Society and Development, v. 10, n. 13, e465101321564, 2021

(CC BY 4.0) | ISSN 2525-3409 | DOI: http://dx.doi.org/10.33448/rsd-v10i13.21564

Nogueira, L. U. H., Lora, E. E. S., \& Trossero, M. A. (2000). Dendroenergia: fundamentos e aplicações. Aneel.

Oliveira Filho, D. (1986). Aquecimento de ar. Centreinar.

Pereira, J. C. D., Sturion, J. A., Higa, A. R., Higa, R. C. V., \& Shimizu, J. Y. (2000). Características da madeira de algumas espécies de eucalipto plantadas no Brasil. Colombo: Embrapa Florestas. Documentos 38.

Puzzi, D. (1986). Abastecimento e Armazenagem de Grãos. Campinas: Instituto Campineiro de Ensino Agrícola, 603p.

Radin, G. \& Maia, C. H. (2015). Custo Energético de Lenha e Cavaco de Madeira para Secagem de Grãos em Agroindústria. Trabalho de Conclusão de Curso. Engenharia Ambiental. Universidade de Rio Verde, Rio Verde.

Ravindra, K., Sokhi, R., \& Van Grieken, R. (2008). Atmospheric polycyclic aromatic hydrocarbons: source attribution, emission factors and regulation. Atmospheric Environment, 42, 2895-2921. 10.1016/j.atmsenv.2007.12.010.

Rodrigues, C. L. C. (2010). Desenvolvimento de um sistema automático para um secador de produtos agrícolas. Tese de Doutorado. Engenharia Agrícola, Universidade Federal de Viçosa, Viçosa. 162p.

Rosegrant, M. W., Magalhaes, E., Valmonte-Santos, R. A., \& D’Croz, D. M. (2015). Returns to Investment in Reducing Postharvest Food Losses and Increasing Agricultural Productivity Growth. Working Paper as of 16 January. Copenhagem Consensus Center. $2015 . \quad$ p. 29. https://www.researchgate.net/publication/276919425_Returns_to_investment_in_reducing_Postharvest_food_losses_and_increasing_Ag_productivity_growth

Sartori, J. A. (2001). Qualidade dos Grãos de Milho após Processo de Secagem. Dissertação de Mestrado. Engenharia Agrícola, Universidade de Campinas, Campinas, 2001.

Serfaty, R. (2007). Combustão e queimadores. CENPES.

Silva, L. C. (2004). Secagem de grãos. Revista Grãos Brasil: Da semente ao consumo, 3 (14), 10-14.

Silva, J. S., Afonso, A. D. L., \& Donzelles, S. M. L. (2000). Secagem e secadores. Aprenda Fácil. 502p.

Toledo, M. C. F., \& Camargo, M. S. F. O. (1998). Benzo(a)pireno em Óleos de Milho Produzidos e Comercializados no Brasil. Ciência e Tecnologia de Alimentos, 18 (1), 1-11. 10.1590/S0101-20611998000100016

Toledo, F. F., \& Marcos Filho, J. (1977). Manual das sementes: tecnologia da produção. Ed. Agronômica Ceres. 224p.

USEPA. (1998). United States Environmental Protection Agency. Semivolatiles organic compounds by gas chromatography/ mass spectrometry (GC/MS) Method 8270D. Acesso em 17 Junho, 2020. http://www.epa.gov

Vlassov, D. (2001). Combustíveis, combustão e câmaras de combustão. UFPR.

Weber, E. A. (2005). Excelência em beneficiamento e Armazenagem de Grãos. Canoas: Livraria e editora Salles. 310p. 